\title{
A Quick But Comprehensive Protocol For Isolation And Short-Term Expansion of Tregs From Peripheral Blood Mononuclear Cells For Treg Therapy In Animal Models And Human In-Vitro Studies
}

\section{Amir Hossein Mansourabadi}

Tehran University of Medical Sciences

Farshid Noorbakhsh

Tehran University of Medical Sciences

Amir Ali Hamidieh

Tehran University of Medical Sciences

Aliakbar Amirzargar ( $\square$ aliakbaramirzargar01@gmail.com )

Tehran University of Medical Sciences https://orcid.org/0000-0003-0328-6924

\section{Research Article}

Keywords: Regulatory T cells, cell culture, MACS, suppression assay, plasticity

Posted Date: February 7th, 2022

DOI: https://doi.org/10.21203/rs.3.rs-1318744/v1

License: (c) (1) This work is licensed under a Creative Commons Attribution 4.0 International License.

Read Full License 


\section{Abstract}

Regulatory T cells (Tregs) are identified via a combination of different extracellular markers, mainly

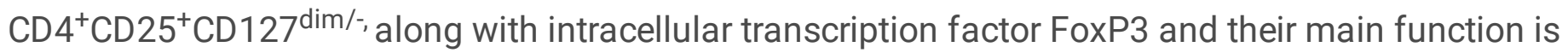
suppression followed by termination of pro-inflammatory immune responses. Tres represent approximately $1-4 \%$ of PBMCs. Hence, therapeutic use of Tregs requires access to an appropriate number of these cells with stable inhibitory potential in the culture medium as well as controlled plasticity in inflammatory conditions. However, based on past studies and experiences, Treg expansion has always faced different challenges in cell biology studies. As the conventional protocols require a complicated and long period of in-vitro expansion of Treg numbers.In this article, we described a feasible, quick, and simple protocol for isolation and expansion of Tregs from PBMCs for in-vitro studies. We also evaluated their suppressive effects and their plasticity for proving their functions although, their conversion to Th17 cells under pro-inflammatory conditions remains a challenge.

\section{Introduction}

One of the latest strategies to induce tolerance in patients in order to prevent transplant rejection is currently under investigation with regulatory Tcells (Tregs)nearing clinical application ${ }^{1}$. Tregsare specialized subpopulation of $\mathrm{CD} 4^{+} \mathrm{CD} 25^{+} \mathrm{CD} 127^{\mathrm{low} /-}$ immune cells that belong to a small proportion of $\mathrm{CD}^{+} \mathrm{T}$ lymphocytes ${ }^{2}$.Tregs act to suppress the immune response via various mechanisms includes inhibition of immune cell proliferation and cytokine production that led to maintaining self-tolerance and homeostasis (Figure 1). Hence, Tregs play a critical role in preventing autoimmunity ${ }^{3}$.Different subsets of Tregs with various functions exist. nTregs (natural Tregs) are generated through MHC class II-dependent TCR interactions in the thymus which results in the high-avidity selection, although further selection mechanisms may occur ${ }^{4-6}$. It is also proved that Foxp3+ Treg cells could also be generated outside the thymus under a variety of conditions ${ }^{7} . C D 4$ CD25 iTregs(induced Treg) are generated in the periphery to control unexpected immune responses under inflammatory conditions, sub-immunogenic antigen presentation and normal homeostasis of the gut ${ }^{8,9}$ (Figure 2).

While a defect in Treg function and number is believed to be associated with the development of several autoimmune diseases, reinforcement of Tregs has been proved to be beneficial in treating autoimmunity as well as in preclinical models ${ }^{10}$.

invitro expanded Tregs can be used for any downstream applicationsuch as suppression assays, cytokine analysis, and gene expression. Also, Treg-based cell therapy has also shown initial promise in clinical trials ${ }^{5}$.As Tregs account only for $5 \%-10 \%$ of the total CD $4+\mathrm{T}$ lymphocytes in the peripheral blood \in-vitro Treg expansion is essential for the clinical applications of these cells ${ }^{11}$. Clinical translation of Treg therapy is also barricaded by other limitations such as lack of an easy and fast method for expansion of Tregs and higher cost associated with GMP-grade cell sorting ${ }^{11-13}$. As the conventional protocols require a complicated and long period of in-vitro expansion of Treg numbers, here we presented 
a feasible and simple protocol using IL-2, anti-CD3/CD28 beads, and rapamycinfor the isolation and expansion of Tregs from peripheral blood mononuclear cells (PBMCs).

\section{Materials And Methods}

\section{$\mathrm{CD}^{+} \mathrm{CD} 25^{+} \mathrm{CD} 127^{\mathrm{dim} /-}$ Treg isolation with MACS technique}

Three cell surface markers include CD4, CD25 and CD127 or two cell surface markers include CD4, CD25 along with one intracellular marker (FOXP3) can be used to isolate Tregs from PBMC. In the current protocol, due to the more feasibility, cheaper, and ease of work, using cell surface markers for Treg isolation is recommended ${ }^{14}$.

The $\mathrm{CD} 4^{+} \mathrm{CD} 25^{+} \mathrm{CD} 127^{\mathrm{dim} /-}$ Treg isolation is performed in a two-simple step. First, labeling the non-CD $4^{+}$ andCD $127^{\text {high }}$ cells using magnetically labeled antibodies and second, using anti-biotin monoclonal antibodies conjugated to Micro Beads. The steps are as follows:

1. Isolation of PBMCs using Ficoll. Dilute the blood sample at 1:1 volume ratio with the appropriate medium (or PBS). Add a volume of density gradient medium to a fresh tube according to the specifications for that density gradient medium. Then, gently layer the diluted blood on top of the density gradient medium. Centrifuge for $30 \mathrm{~min}$ at $400 \mathrm{~g}$ with the break off. Aspirate plasma and platelets on the upper layer using a sterile pipette to avoid platelet contamination. harvest the cells by inserting he pipette directly through the upper plasma layer to the mononuclear cells at the interface. Finally, wash the harvested cells twice in the appropriate buffer for $5 \mathrm{~min}$ at $300 \mathrm{~g}$. The cells are now ready for cell separations ${ }^{15,16}$.

2. Treg cell separationusing MACS column, step1.In the first place, the cell number should be determined and the cell suspension should be spun at $300 \mathrm{~g}$ for $10 \mathrm{~min}$ followed by aspiration of the supernatant. Then, the cell pellet should be resuspended in $40 \mu \mathrm{L}$ of MACS buffer (PBS with $2 \mathrm{mM}$ EDTA and $0.5 \%$ BSA) per $10 \otimes$ total cells. $10 \mu \mathrm{L}$ of $\mathrm{CD} 4^{+} \mathrm{CD} 25^{+} \mathrm{CD} 127^{-}$biotinylated antibody per $10 \otimes$ total cells should be added followed by incubation for $5 \mathrm{~min}$ in $2-8{ }^{\circ} \mathrm{C}$. In the following, $20 \mu \mathrm{L}$ of Anti-Biotin microbeads and $30 \mu \mathrm{L}$ of MACS buffer per $10 \otimes$ total cells should be added followed by second incubation for $10 \mathrm{~min}$ in 2-8 ${ }^{\circ} \mathrm{C}$. Before Applying the cell suspension onto the LD MACS column, the column should be rinsed using $2 \mathrm{~mL}$ of MACS buffer. In this step, pass-through cells should be collected after adding the mentioned cell suspension onto the column. The cells resulting from this step are unlabelled $\mathrm{CD} 4^{+}$cell fractions ${ }^{17,18}$.

3. Treg cell separation using MACS column, step2. Centrifuge the cells obtained from the previous step at $300 \mathrm{~g}$ for $10 \mathrm{~min}$ and remove the supernatant completely. In the following, the cell pellet should be resuspended in $90 \mu \mathrm{L}$ of MACS buffer per $10 \otimes$ total cells. At this step, $10 \mu \mathrm{L}$ of CD25 Beads per $10 \otimes$ total cells should be added followed by incubation for $5 \mathrm{~min}$ in $2-8^{\circ} \mathrm{C}$. at the last step, cells should be washed once by adding $1 \mathrm{~mL}$ of MACS buffer and centrifuge for 10 minutes at $300 \mathrm{~g}$ and supernatant should be 
discarded immediately. before adding the washed cells to the MS column, cell pelleted should be resuspended in $0.5 \mathrm{~mL}$ of MACS buffer per 108 total cells. Before Applying the cell suspension onto the MS MACS column, the column should be rinsed using $0.5 \mathrm{~mL}$ of MACS buffer. in this step, cell suspension should be added to the pre-washed MS column. flow-through obtained from this step is containing unlabelled cells ${ }^{19}, 20$.

Remove the MS column from the stand and place it on sterile $15 \mathrm{~mL}$ conical falcon tubes. now to separate magnetically labelled cells from the MS column, $1 \mathrm{~mL}$ of MACS buffer should be added onto the MS column and the plunger must be pushed Immediately and firmly. The flow-through obtained at this stage contains the Tregs we are looking for.

\section{Flowcytometry analysis of isolated $\mathrm{CD} 4^{+} \mathrm{CD} 25^{+} \mathrm{CD} 127^{\mathrm{dim} /-}$ Tregs}

Isolated cells should be washed with fresh and complete TEXMACS medium at $1500 \mathrm{rpm}$ for $5 \mathrm{~min}$ at $4^{\circ} \mathrm{C}$ and the supernatant should be discarded. Single cell suspensions should be incubated with $2 \mu \mathrm{L}$ of FITCconjugated anti-CD 4, $2 \mu \mathrm{L}$ of APC-conjugated anti-CD 25 and $2 \mu \mathrm{L}$ of PE-conjugated anti-CD25 per $10^{6}$ total cells for $30 \mathrm{~min}$ on the ice (or in the $4^{\circ} \mathrm{C}$ ).

After incubation period, stained cells should be washed twice with $500 \mu$ Lof flowcytometry buffer (PBS with $1 \% \mathrm{BSA}$ and $0.1 \%$ sodium azide) at $1500 \mathrm{rpm}$ for $5 \mathrm{~min}$ at $4^{\circ} \mathrm{C}$ and the supernatant should be discarded. At the end, $500 \mu$ Lof flowcytometry buffer should be added and data should be collected with flow cytometry(Figure 3A and 3B). Delays of more than 24h may increase the chance of obtaining falsenegative or false-positive hence, we recommend fixing the cells using $4 \%$ paraformaldehyde solution (diluted in PBS) and storing the fixed cells at 2 to $8^{\circ} \mathrm{C}$.

\section{Fast and simple protocolfor TregExpansionInvitro}

Tregs isolated from the PBMC of beta-thalassemia major kids expanded rapidly with comparable foldexpansion during the 5 days of culture. At day 0 , isolated Tregs should be cocultured with $50-100 \mathrm{IU} / \mathrm{ml}$ pen-strep, $1 \mathrm{mM}$ Sodium pyruvate (C3H3NaO3), 25 mMHepes, 100nM rapamycin, $500 \mathrm{IU}$ IL-2, and 10\% human AB serum (or FBS) in TEXMACS medium ${ }^{21}$. Isolated Tregs should be also activated with anti$\mathrm{CD} 3 / \mathrm{CD} 28$ coated beads at a $4: 1$ bead:cell ratio at day 0 .Fresh culture medium containing $500 \mathrm{IU} / \mathrm{ml} \mathrm{IL}-2$ should be added at day 3 and day 5 post-expansion.Flow cytometric analysis should be performed on harvested cells at day 5 post-expansion. Briefly, cells should be washed and stained with the mentioned antibodies in part 4 for $30 \mathrm{~min}$ at $4^{\circ} \mathrm{C}$. Appropriate isotype control antibodies should be used for each sample. Following staining, cells were examined by flow cytometry (Figure 3C, 3D and 3E).

\section{Functional assay of expanded Tregs}

We took advantage of Treg functional (suppression) assays to evaluate the functional effect of expanded Tregs on responding T cells (Tresp). This assay was performed by co-culturing the responding population 
with the in-vitro expanded Tregs.Responder T cells were obtained from PBMCs using MACS by negative selection.

For assessing the proliferation of Tresp in the presence of expanded Tregs, Tresp should be labeled using carboxyfluoresceinsuccinimidyl ester (CFSE) dye in the first place. For this purpose, isolated Tresp should be washed and the pellet should be resuspended in $1 \mathrm{ml}$ PBS containing $0.1 \%$ BSA per $2 \times 106$ total cells.

$1 \mu \mathrm{L}$ of $5 \mathrm{mM}$ CFSE dye should be added followed by incubation in a dark place at room temperature (RT) for $15 \mathrm{~min}$. After the incubation period, $10 \mathrm{ml}$ of cold complete culture medium should be added and the tube should be incubated again on the ice for $5 \mathrm{~min}$. In the next step, cells should be washed with a complete culture medium twice to discard unattached and additional CFSE. Now, labeled Tresps are ready for suppression assay ${ }^{22} .1 \times 10^{5}$ per well of Tresp should be co-cultured with Tregs at different ratios (Treg: Teff $=2: 1$ and 8:1) in TEXMACS medium supplemented with 10\% FBS and in the presence of antiCD3/CD28-coated beads at a 4:1 bead:cell ratio in 24-well flat-bottom plates.Cells should be incubated at $37^{\circ} \mathrm{C}$ in the presence of $5 \% \mathrm{CO} 2$ and $98 \% 02$ for 5 days. After harvesting the cells, the proliferation of CFSE-labelled Tresps should be determined using flow cytometry (Figure 3J).

\section{Treg plasticity in the inflammatory environment is the most challenging aspect}

Treg plasticity and their conversion to producing inflammatory cytokine cells in the presence of proinflammatory cytokines are the major concerns in Treg immunotherapy.Plastic Tregs have several features of Th cells including the expression of specific transcription factors in Th cells and the secretion of Th-related cytokines, while still maintaining the expression of specific transcription factors for Treg ${ }^{23}$, ${ }^{24}$. Hence, the plastic differentiation of Tregs not only shows an association with changes in the stability of Tregs but also increases the complexity of the immune circumstances under inflammatory conditions, especially autoimmune diseases. Signalling through IL-1 receptor and IL-6 receptor in combination with signalling through TGF- $\beta$ receptor and TCR engagement, induces strong expression of STAT3 (Signal Transducer and Activator of Transcription 3) and RORYT (Retinoic acid-related orphan receptor gamma T) transcription factors which drive the differentiation of conventional T cells to a Th17 lineage in inflammatory conditions ${ }^{22}$. The capacity of Tregs to adopt a Th1 phenotype has been also demonstrated in murine models ${ }^{25}$. Nevertheless, the plasticity of the human Treg compartment is still uncharacterized. Moreover, it is not clear to what extent cytokine production by Tregs is due to true plasticity rather than to heterogeneity in the population. Hence, assuming that naive Tregs are capable of upregulating the expression of Th17-associated IL-17 in response to inflammatory cytokines, we simulated inflammatory conditions for expanded Tregs in the culture medium. For this purpose, already expanded Tregs were cultured for $72 \mathrm{~h}$ in a medium containing $10 \mathrm{ng} / \mathrm{ml} \mathrm{IL-}-1 \beta, 4 \mathrm{ng} / \mathrm{ml} \mathrm{IL-6,5} \mathrm{ng/ml} \mathrm{TGF-} \beta$ and $10 \mathrm{IU} / \mathrm{ml} \mathrm{IL-2}$ with or without $500 \mathrm{nM}$ rapamycin (Figure 3F-3I). After harvesting the cells, intracellular staining for IL-7 was done as follows:

After harvesting the Tregs, a single-cell suspension at a concentration of $1 \times 106$ cells $/ \mathrm{mL}$ in cell straining buffer(PBS containing 2\% FBS) should be prepared. For the fixing step, $1 \mathrm{~mL}$ fixation buffer (PBS containing $1 \%$ paraformaldehyde) per $1 \times 10^{6}$ cells should be added followed by incubation for $15 \mathrm{~min}$ at 
RT. After Centrifuging at $500 \mathrm{~g}$ for 5 min at RT, supernatant should be discarded to remove the fixation buffer and a second and third wash of fixed cells with cell staining buffer should be done at $500 \mathrm{~g}$ for 5 $\min$.

For permeabilizing the cells, fixed cells should be resuspended in $1 \mathrm{~mL}$ permeabilization buffer $(0.2 \%$ Tween) per $1 \times 106$ cells and centrifuge at $500 \mathrm{~g}$ for 5 minutes at RT followed by removing the supernatant. In the following $\mathbb{\text { fixed }}$ and permeabilized cells should be washed twice with $0.1 \%$ Tween.

For the staining step, in the first place, the primary antibody should be Diluted with permeabilization buffer for an optimal working concentration. Fixed and permeabilized cells should be resuspended in PBS containing $2 \%$ FBS, $0.1 \%$ Tween, and $2 \mu \mathrm{L}$ of PE-conjugated anti-IL-17 antibody solution followed by Incubate for $20 \mathrm{~min}$ on the ice (or at $4^{\circ} \mathrm{C}$ ). After the incubation period, the cells must be centrifuged at 500 $\mathrm{g}$ for $5 \mathrm{~min}$ at $4^{\circ} \mathrm{C}$ followed by discarding the supernatant and washed twice with $0.1 \%$ Tween (or permeabilization buffer). As the last step, fixed, permeabilized, and intracellular stained Tregs should be resuspended in $500 \mathrm{uL}$ of cell staining buffer for final analysis.The intracellular expression of IL-17 should be determined using flow cytometry.

\section{Commentary}

The feasibility of Treg therapy depends on success in the expansion of sufficient Treg cell numbers invitro. Using our described protocol for isolation and expansion of Tregs, the appropriate number of $\mathrm{CD} 4^{+} \mathrm{CD} 25^{+} \mathrm{CD} 127^{\mathrm{dim} /-}$ Tregs could be achieved for animal and in-vitro studies in a short period of time. Also, the functional assay of Tregs after expansion using our protocol showed that the expanded cells maintained their inhibitory function, especially at higher doses (1:8 Tresp: Treg). Reaching a larger number of cells requires longer cultivation.

Tregs have been demonstrated plastic differentiation in inflammatory situations, and their stability, which is characterized by the stable expression of specific factors, becomes abnormal.

Our data also confirmed that over the $72 \mathrm{~h}$ culture period in the presence of inflammatory cytokines and in the absence of rapamycin, intracellular expression of IL-17 in Tregs showed upregulation compared to the baseline, while rapamycin resulted in the production of a stable population of Tregs with a reduction in the intracellular expression of IL-17 in Tregs compared to the group without rapamycin. Therefore, to maintain the plasticity and stability of expanded Tregs in clinical studies, it is recommended to use immunosuppressive drugs such as rapamycin along with Treg therapy.

\section{Declarations}

\section{Funding}

This work was supported by [National Institute for Medical Research Development (NIMAD)(grant Number[995705]) andlran National Science Foundation (INSF) (grant number [98002620]), and Tehran 
University of Medical Sciences (grantnumber[98-01-30-41768])]. The authors also acknowledge the Department of Immunology, School of Medicine, Tehran University of Medical Science, for their assistance.

\section{Competing Interests}

The authors have no relevant financial or non-financial interests to disclose.

\section{Author Contributions}

All authors contributed to the study conception and design. Material preparation, data collection and analysis were performed by [Amir Hossein Mansourabadi], [FarshidNoorbakhsh] and [AliakbarAmirzargar]. The first draft of the manuscript was written by [Amir Hossein Mansourabadi], and [FarshidNoorbakhsh]and [Amir Ali Hamidieh]. and all authors commented on previous versions of the manuscript. All authors read and approved the final manuscript.

\section{Ethics approval}

This study was performed in line with the principles of the Declaration of Helsinki. Approval was granted by the Ethics Committee of University B (Date2019/No IR.TUMS.MEDICINE.REC.1398.566).

\section{Consent to publish}

The authors affirm that human research participants provided informed consent for publication of the images in Figures 3A-3J.

\section{References}

1. Tang Q, Vincenti F. Transplant trials with Tregs: perils and promises. J Clin Investig. 2017;127(7):2505-12.

2. Romano M, Fanelli G, Albany CJ, Giganti G, Lombardi G. Past, present, and future of regulatory T cell therapy in transplantation and autoimmunity. Front Immunol. 2019;10:43.

3. Bluestone JA, Tang Q. Treg cells-the next frontier of cell therapy. Science. 2018;362(6411):154-5.

4. Dall'Era M, Pauli ML, Remedios K, et al. Adoptive Treg cell therapy in a patient with systemic lupus erythematosus. Arthritis \& Rheumatology. 2019;71(3):431-40.

5. Göschl L, Scheinecker C, Bonelli M, editors. Treg cells in autoimmunity: from identification to Tregbased therapies. Seminars in immunopathology; 2019.

6. Mansourabadi AH, Khosroshahi LM, Noorbakhsh F, Amirzargar A. Cell therapy in transplantation: A comprehensive review of the current applications of cell therapy in transplant patients with the focus on Tregs, CAR Tregs, and Mesenchymal stem cells. Int Immunopharmacol. 2021;97:107669.

7. Gyori D, Lim EL, Grant FM, et al. Compensation between CSF1R+ macrophages and Foxp3+ Treg cells drives resistance to tumor immunotherapy. JCl insight. 2018;3(11). 
8. Kim S-H, Saba E, Kim B-K, et al. Luteolin attenuates airway inflammation by inducing the transition of CD4+ CD25-to CD4+ CD25+ regulatory T cells. Eur J Pharmacol. 2018;820:53-64.

9. García E-M, Galicia-Carreón J, Novak N. In vitro Conversion into CD4+ CD25+ Foxp3+ Induced Regulatory T Cells Is Reduced in Atopic Dermatitis Patients. Int Arch Allergy Immunol. 2020;181(5):353-6.

10. Miao J, Zhu P. Functional defects of Treg cells: New targets in rheumatic diseases, including ankylosing spondylitis. Curr Rheumatol Rep. 2018;20(5):1-8.

11. Li P, Wang L, Zhou Y, et al. C-C Chemokine Receptor Type 5 (CCR 5)-Mediated Docking of Transferred Tregs Protects Against Early Blood-Brain Barrier Disruption After Stroke. J Am Heart Association. 2017;6(8):e006387.

12. Jiang W, Li X, Ding H, et al. PD-1 in Tregs predicts the survival in sepsis patients using sepsis-3 criteria: A prospective, two-stage study. Int Immunopharmacol. 2020;89:107175.

13. Liu Q, Dwyer GK, Zhao Y, et al. IL-33-mediated IL-13 secretion by ST2+ Tregs controls inflammation after lung injury. JCl insight. 2019;4(6).

14. Schoenbrunn A, Frentsch M, Kohler S, et al. A converse 4-1BB and CD40 ligand expression pattern delineates activated regulatory $T$ cells (Treg) and conventional $T$ cells enabling direct isolation of alloantigen-reactive natural Foxp3+ Treg. J Immunol. 2012;189(12):5985-94.

15. Jia Y, Xu H, Li Y, et al. A modified Ficoll-Paque gradient method for isolating mononuclear cells from the peripheral and umbilical cord blood of humans for biobanks and clinical laboratories. Biopreserv Biobank. 2018;16(2):82-91.

16. Gill PK. Rapid isolation of peripheral blood mononuclear cells from whole blood with ficoll hypaque density centrifugation. J Int Res Med Pharm Sci. 2019;14:17-20.

17. Zhou Y, Grieser AM, Do J, Itsara LS, Vaughan AM, Ghosh AK. Purification and production of Plasmodium falciparum zygotes from in vitro culture using magnetic column and Percoll density gradient. Malar J. 2020;19:1-10.

18. Karimi N, Oloomi M, Orafa Z. Circulating Tumor Cells Detection in Patients with Early Breast Cancer Using MACS Immunomagnetic Flow Cytometry. Avicenna J Med Biotechnol. 2020;12(3):148.

19. Milward K, Hester J, Wood KJ. Isolation of human regulatory T lymphocytes by fluorescenceactivated cell sorting. Immunological tolerance: Springer; 2019. pp. 43-54.

20. Ren Q, Jiang C, Liu J. CFDA-SE Combined with MACSiBeads ${ }^{\mathrm{TM}}$ Particles to Evaluate the Inhibitory Effect of Treg Cells in vitro. Annals of Clinical \& Laboratory Science. 2019;49(6):740-7.

21. Fraser $\mathrm{H}$, Safinia N, Grageda N, et al. A rapamycin-based GMP-compatible process for the isolation and expansion of regulatory T cells for clinical trials. Mol Therapy-Methods Clin Dev. 2018;8:198209.

22. Safinia N, Grageda N, Scottà C, et al. Cell therapy in organ transplantation: our experience on the clinical translation of regulatory T cells. Front Immunol. 2018;9:354. 
23. Lee YK, Mukasa R, Hatton RD, Weaver CT. Developmental plasticity of Th17 and Treg cells. Curr Opin Immunol. 2009;21(3):274-80.

24. Kleinewietfeld M, Hafler DA, editors. The plasticity of human Treg and Th17 cells and its role in autoimmunity. Seminars in immunology. Elsevier; 2013.

25. Koch MA, Perdue NR, Killebrew JR, Urdahl KB, Campbell DJ. The transcription factor T-bet controls regulatory $T$ cell homeostasis and function during type 1 inflammation. Nat Immunol. 2009;10(6):595-602.

\section{Figures}

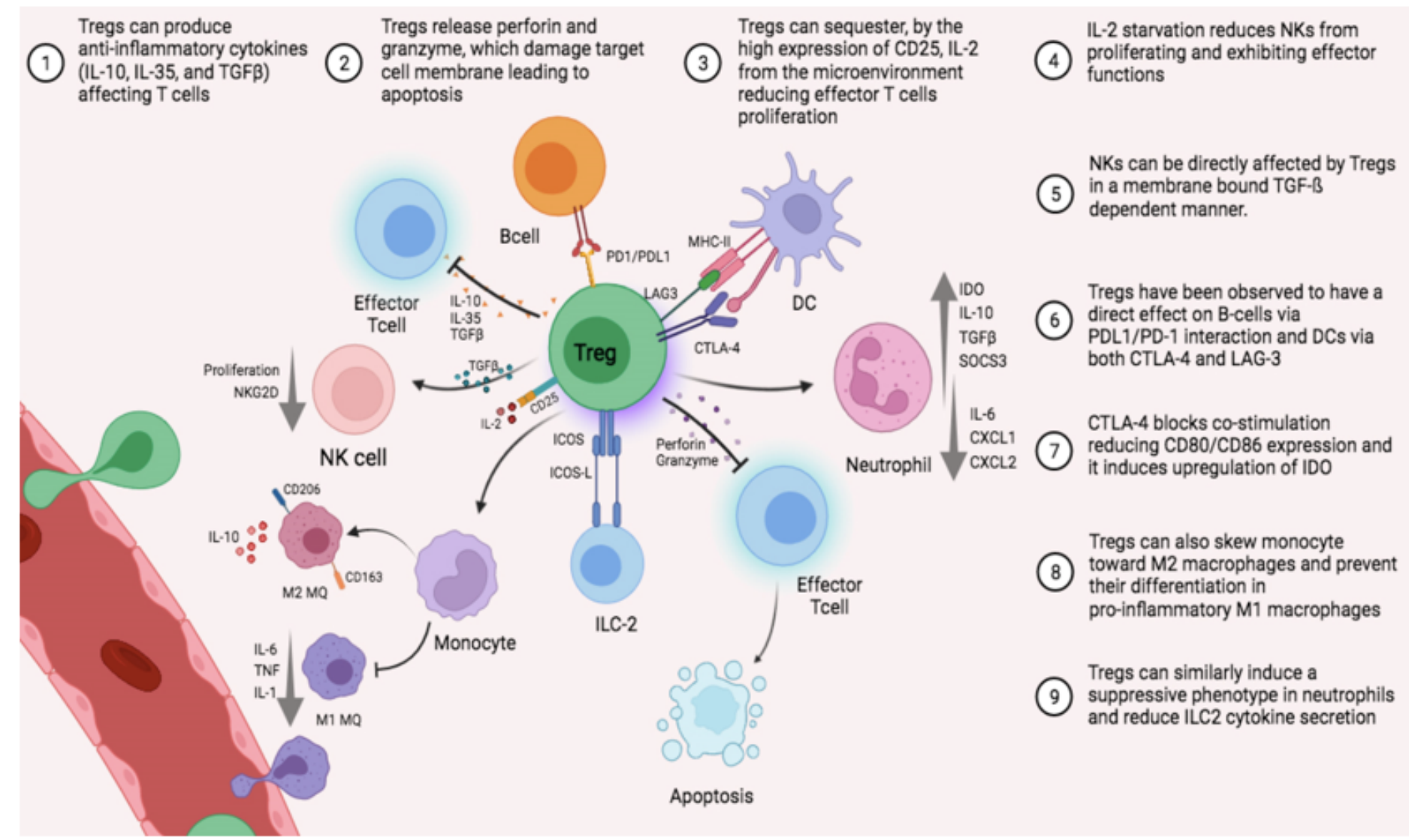

Figure 1

Treg suppressive mechanisms. 


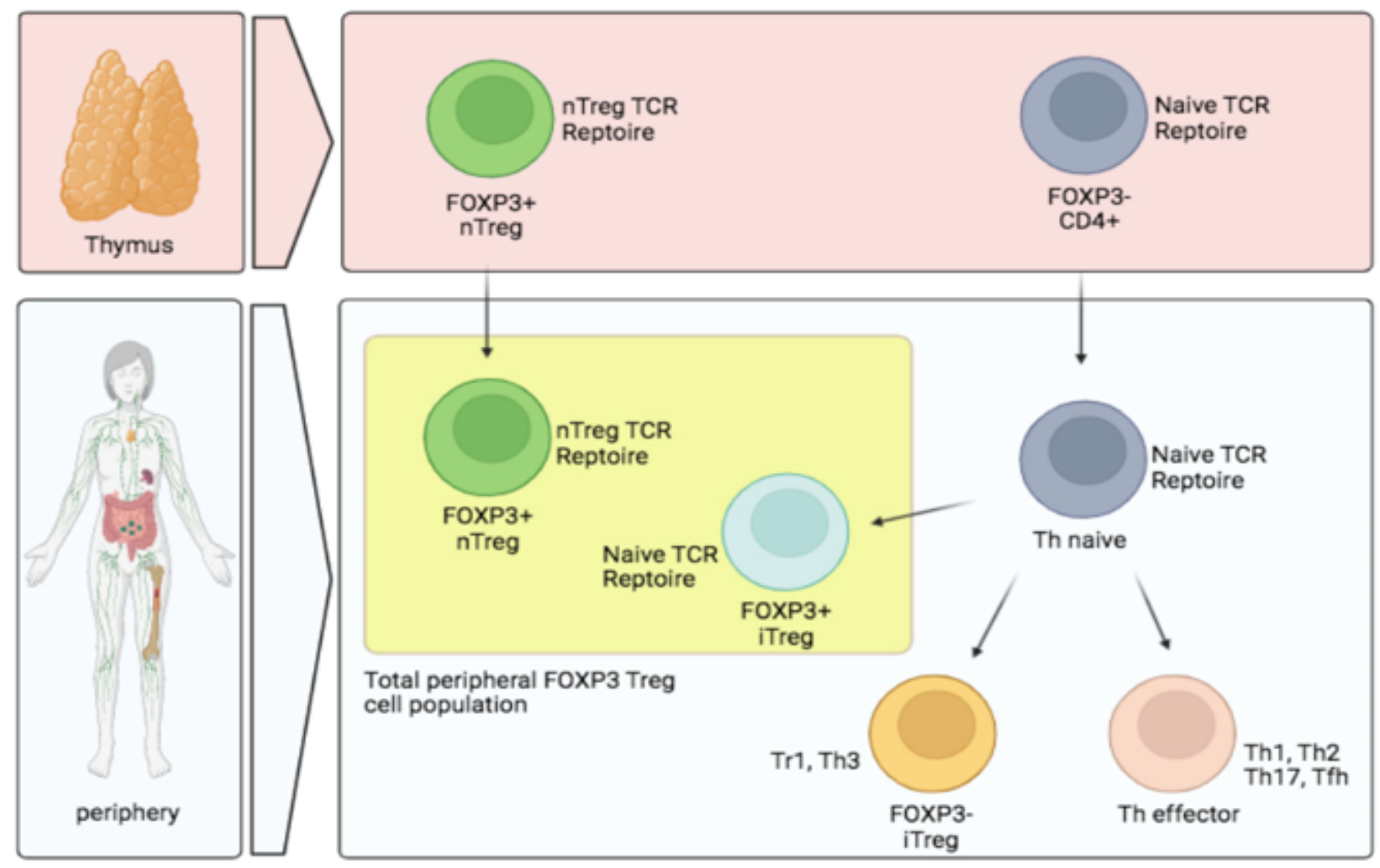

Figure 2

Generation of Tregs in different anatomical sites. nTregs differentiate in the thymus followed by migrating to peripheral tissues. iTregs differentiate in peripheral organs and secondary lymphoid organs. The circulating population of Tregs is comprised of both iTregs and nTregs. It is thought that iTregs and nTregs differ in their TCR repertoire because iTregs are derived from naive TCD4+ cells in the periphery. 

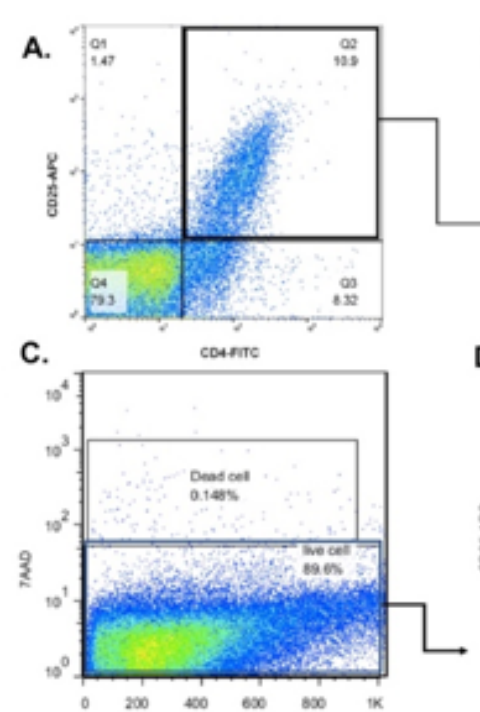

F.
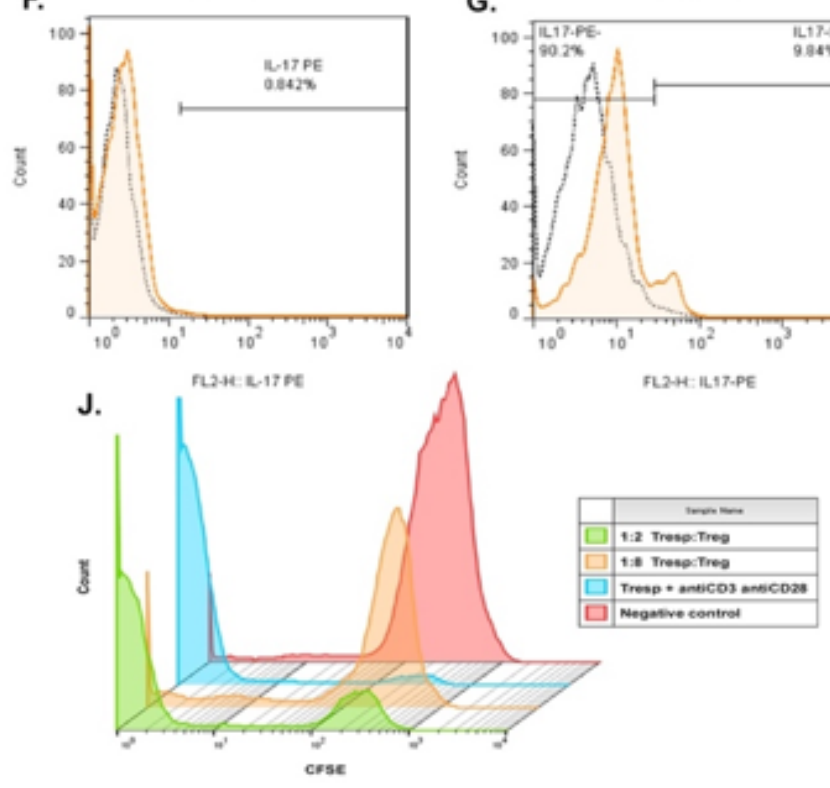

E.

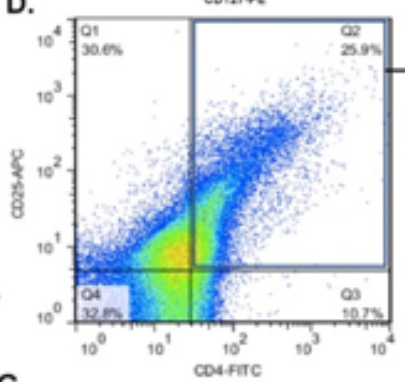

G.

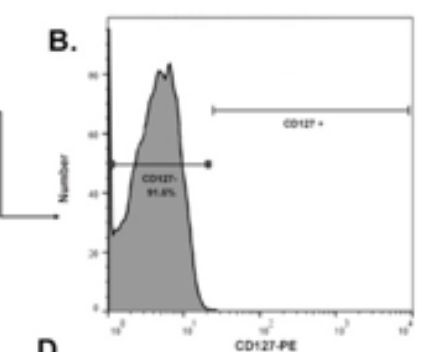

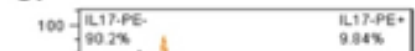

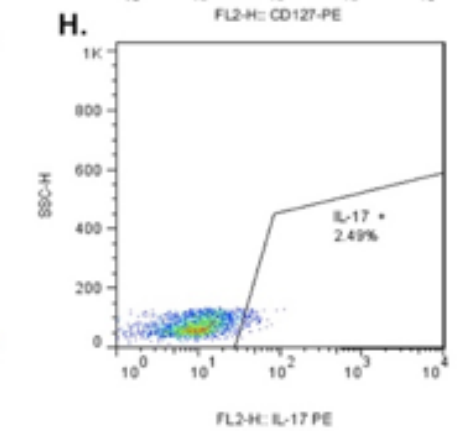

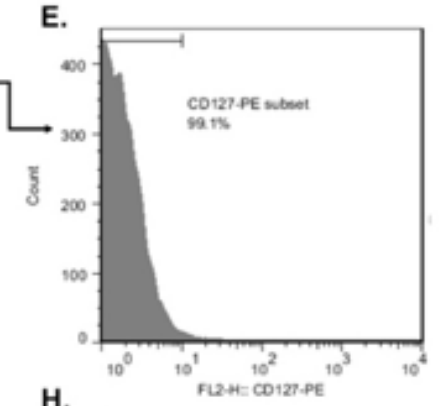

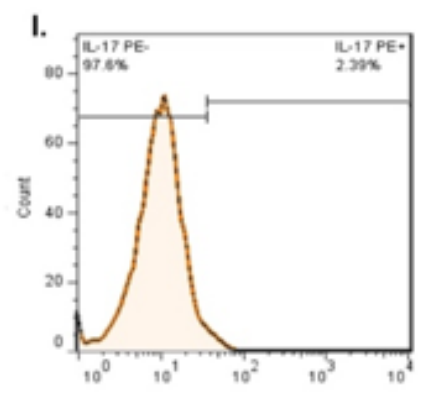

\section{Figure 3}

Treg purification from the human PBMC using MACS column, percentage after short-term expansion and the plasticity in the presence of inflammatory cytokine. gating on CD4+CD25+ population before expansion (A). The percent of CD127- cells in the population of CD4+CD25+ cells is shown (B). Live/dead exclusion using 7-AAD (a nucleic acid binding dye). They are excluded by live cells, as these dyes are not membrane permeable (C). Gating on $\mathrm{CD} 4^{+} \mathrm{CD} 25^{+}$population after expansion using $100 \mathrm{nM}$ rapamycin, 500 IU IL-2, and $10 \%$ human AB serum and in the presence of anti-CD3/CD28 microbeads (D). The percent of $\mathrm{CD} 127^{-}$cells in the population of gated $\mathrm{CD} 4^{+} \mathrm{CD} 25^{+}$cells is shown (E). Expression of IL-17 in the Tregs in the absence of inflammatory cytokines (baseline) (F). Expression of IL-17 in the Tregs that expanded in a medium containing $10 \mathrm{ng} / \mathrm{ml} \mathrm{IL}-1 \beta, 4 \mathrm{ng} / \mathrm{ml} \mathrm{IL-}-6,5 \mathrm{ng} / \mathrm{ml}$ TGF- $\beta$ and $10 \mathrm{IU} / \mathrm{ml} \mathrm{IL-2}$ without rapamycin for $72 \mathrm{~h}(\mathrm{G})$. Intracellular staining for $\mathrm{IL}-17$ in the Tregs that expanded in a medium containing

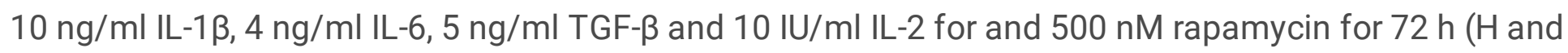
I). The suppressive ability of expanded Tregs was assessed as the percentage decrease of Tresp 
proliferation in the presence of two different ratios of Tregs. The calculation should be based on the proliferation of Tresp in the presence of anti-CD3/CD28 beads compared with the proliferation of cultures also containing expanded Tregs $(\mathrm{J})$. 